\title{
Risk Assessment of Aflatoxin and Fumonisin in Fish Feeds, Kenya A Review
}

\author{
Salome J. Chelimo ${ }^{1 *} \quad$ Job Isaboke $^{2} \quad$ Odipo Osano $^{2} \quad$ Diana Menya $^{3}$ \\ 1. Department of Health Services, Baringo County \\ 2. Department of Environmental Biology and Health, School of Environmental Studies University of Eldoret \\ 3. Department of Epidemiology and Biostatistics, School of Public Health Moi University
}

\begin{abstract}
Fish is a protein source and constitutes other significant nutrients that have been crucial to human health. Aquaculture in Kenya has grown faster than any other food production sector, with fish feeds being prepared from different cereal products commonly contaminated by Mycotoxins. But controlling the growth of fungi that cause mycotoxin has been a challenge due to conditions that enable their development. With fish contamination primarily ignored, there is still high consumption of fish being propagated by improved and increased aquacultural activities. There have been various qualitative and quantitative assessments on Aflatoxin and Fumonisin in animal feed and food with little focus on fish feed which might be the most significant risk factor for cancer development. Kenya's high occurrence warranted the current review, which describes sources of fish feeds, conditions for mould growth, exposure of fish too contaminated feeds, decontamination of fish feed and feed ingredients, effects of Fumonisin and Aflatoxin on fish and human, risk characterization and management strategies. This review provides a platform and insights to novice researchers to pave the way for future research in the area.
\end{abstract}

Keywords: Mycotoxins; Aflatoxins; Fumonisin; Uasin Gishu; Kisumu.

DOI: $10.7176 / \mathrm{JBAH} / 11-10-05$

Publication date:May $31^{\text {st }} 2021$

\section{Introduction}

Mycotoxins are secondary toxins produced by mycotoxigenic fungi as metabolites of genera Aspergillus, Fusarium, and Penicillium (Nazhand, Durazzo, Lucarini, Souto, \& Santini, 2020). Mycotoxins that contaminate formula feed and feed material grain include Aflatoxin, Ochratoxin, Zearalenone, Deoxynivalenol, Nivalenol, Fumonisin, T-2 toxin, Citrinin, and Sterigmatocystin (Sulyok, Krska, \& Schuhmacher, 2010). But of tremendous significance in most tropical countries like Kenya are Aflatoxin and Fumonisin. These types contaminate various agricultural commodities such as corn, wheat, peanuts, and Sorghum, causing diverse toxic effects to humans and animals (Njeru, Midega, Muthomi, Wagacha, \& Khan, 2019).

Aflatoxins are the common mycotoxins produced mainly by the fungi Aspergillus flavus and A. parasiticus, which grow on numerous feeds when environmental conditions are favourable (Tarus, Rachuonyo, Omega, \& Ochuodho, 2019). They are usually poisonous fungal by-products that cause adverse health effects when consumed and are known to be potent genotoxic with carcinogenic effects. Fumonisin is a type of primary mycotoxin produced by Fusarium verticillioides that widely contaminate feed material crops (Moretti, Logrieco, \& Susca, 2017). They are classified as $2 \mathrm{~B}$ carcinogens and toxins that promote cancers (Mutiga, Hoffmann, Harvey, Milgroom, \& Nelson, 2015). Fumonisin has continuously been associated with a high incidence of esophageal and hepatic cancer in China and most parts of Africa, where its contaminations are highly frequent.

Cancer is the third leading cause of death and the second among the non-communicable disease (NCD) to cause the highest mortality in Kenya with noted social-economic impacts, including increased pre-mature deaths, high cost of care and loss of productivity. Liver cancer is ranked fourth leading causes of mortality among other cancers; Breast, prostate, lung, bladder, colorectal, with hepatocellular carcinoma being identified as the primary cause of death (Ochwoto et al., 2019). Also the rising incidence rate in Kenya, and despite the advanced diagnosis the survival rate remains at $12 \%$ at a span of 5years. According to (Mutiga et al., 2015), chronic exposure to Aflatoxin and Fumonisin which are persistent risk factors, increases the progression of Human Immunodeficiency Virus and Hepatitis B Virus (HIV and HBV) which are precursors to the development of Hepatocellular Carcinoma (HCC).

The high prevalence of HCC is high in counties with a high prevalence of HIV (C. Chen, Riley, \& Wu, 2018). HIV and cancers are the $3^{\text {rd }}$ causes of mortality nationally, with the highest numbers of deaths recorded in the Western region including Kisumu (Obonyo \& Salano, 2018). A study by Kigen (2017) on five-year data from the Eldoret cancer registry indicates high prevalence of cancer in Uasin Gishu county, with esophageal cancer being the most common and especially among the Kalenjins. Further, suggestions from the study showed the potential associations to be consumption of traditional alcohol (Busaa or changaa) attributed to the use of contaminated animal feeds and maize flour used in the fermentation of the alcohol.

Kenya is still grappling with risk factors attributed to increased urbanization and industrialization, i.e. 
environmental and aquaculture, thus increasing toxins to animals and humans. Research shows that up to $40 \%$ of estimated cases of cancers can be prevented by avoiding risk factors through implementing evidence-based interventions (Kenya cancer policy 2019-2030). Despite the improved diagnosis, treatment and awareness within communities, the burden of cancer continues to rise in the country that is coupled with immense challenges. There is still insufficient general knowledge to the public, pathology and radiology services are weak, with inadequate infrastructure and human resources (Makau-Barasa et al., 2020). Other serious issues surround the affordability and availability of cancer commodities, which impedes access to services by cancer patients. The prices of drugs are notably high, with most patients unable to raise. Additionally, insurance covers do not support an evidence-based standard of care for all up to survivorship care. Most patients incur many expenses from the time they are diagnosed, of which some of them come when already in stage four, forcing them to spend and even fundraised to get immediate management. This leaves most families in a deep state of poverty and continuous loss of loved ones.

Consumption of contaminated animal feed \& food with Aflatoxin and Fumonisin in Kenya is known to be through dietary exposure that has been evidenced from the past outbreaks (Strosnider et al., 2006). Most exposures occurred through direct eating of contaminated crops and indirect consumption where toxins are transferred through bioaccumulation in milk, eggs, and beef. However, fish have not been studied exhaustively (Sirma, Makita, Grace Randolph, Senerwa, \& Lindahl, 2019). With fish contamination primarily ignored, there is high consumption of fish being propagated by improved and increased aquacultural activities (Sirma et al., 2019). There have been various qualitative and quantitative assessments on Aflatoxin and Fumonisin in animal feed and food with little focus on fish feed which might be the most significant risk factor for cancer development. Kenya's high occurrence warrants the need to review its occurrence, consumption of contaminated fish feed concerning human risks, and management using a scenario tree depicted in the figure below.

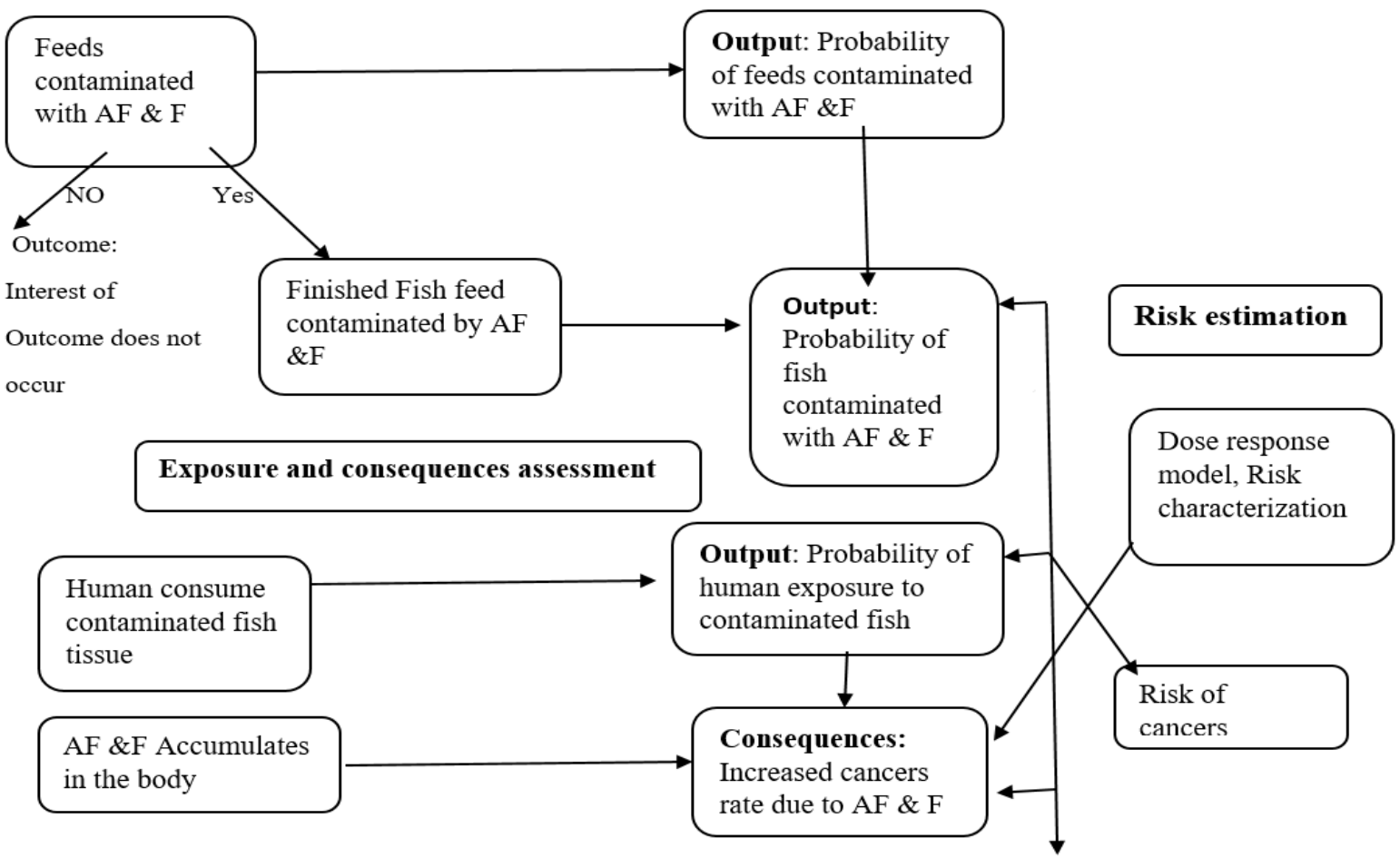

Fig 1:A scenario tree of cancer development risks following consumption of Aflatoxin and Fumonisin contaminated fish.

\section{Risk assessment}

\section{Sources of fish feed in Kenya}

Fish is a protein source and constitutes other significant nutrients that have been crucial to human health. Aquaculture in Kenya has grown faster than any other food production sector at an annual rate of 5.8\% (Oliveira \& Vasconcelos, 2020), and that this trend is expected to continue. Fish might be a significant source of food in the future because it is currently contributing up to $62.0 \%$ as food for human consumption, therefore holding the future food basket (Vitousek et al., 2009). But with the growth of this industry, aquaculture remained a priority in Kenya. Various initiatives including economic stimulus programme (ESP) was undertaken to ensure high consumption of fish and as well encourage farmers to produce more as a way of boosting the economy (Muteti, 
Lokuruka, \& Yasindi, 2019). Though the fish farming programme underwent a remarkable revolution with an increase in fish production since 2010 (Benard, Dulle, \& Lamtane, 2018), there was a considerable gap in their feeds that would boost their productivity. Research showed that $99.9 \%$ of small-scale farmers and noncommercial tilapia farmers in Kenya rely on pond production, with 104 tonnes of feed supplementation by the formal feed sector since 2005 (Nyandat, 2007). However, it was found that for 1,000 fish to be produced, 2,500 tonnes of fish feeds were needed. Therefore, their increased supply of feeds could probably be associated with the increased probability of exposure of fish to contaminated feeds.

Fish feed has recently become an option in replacing fishmeal making it the major component in any fish productivity. However, in order to have quality fish produced from aquaculture, there is need to provide nutritionally balanced feed (Nzevu, Amwata, \& Mutua, 2018). In developing countries like Kenya, fish farmers prefer locally made fish feeds or commercially imported feed, with pellets and mash being the most used feeds (Marijani, Charo-Karisa, Kigadye, \& Okoth, 2020). Though several research shows that majority of Kenyan fish farmers locally make fish feeds or commercially import feeds for their daily production with most of the small scale farmers depending on traditional feed ingredients such as wheat flour, rice bran, which are prone to contaminations (Rani \& Kumar, 2020). To make a balanced diet, fish feeds are formulated by mixing a more comprehensive range of such ingredients, including significant cereals produced in Kenya which are the leading staple food that are cheap and available (Marijani, Kigadye, \& Okoth, 2019). Therefore, it can be concluded that finished fish feeds might be contaminated while handling the ingredients and probably at the storage points. The most common ingredients used in Kenya for both commercial and homemade fish feeds are;

Commercial fish feeds ingredients

Home- made fish feed ingredients
1. Ground nut oil cake
2. Rice bran
3. Soy bean oil cake
4. Molasses
5. Bone meal
6. Cotton seed cake
7. Omena fish meal
8. Maize gluten meal
1.Maize
2. Sorghum
3.Shrimps
4. Omena
5. Cassavas
6. Soy beans
7. Ground nuts
8. Rumen content
9.Kales
10. Sun flower
11. Ochonga

Source; (Marijani et al., 2019), (Munguti, Kim, \& Ogello, 2014).

\section{Conditions conducive for the growth of Aflatoxin and Fumonisin}

Fumonisin and Aflatoxin are the most frequent contaminants to food crops, especially in hot and humid climates, as in sub-Saharan Kenya, their staple food is cereals (Turner, 2013). However, Kimanya (2008) found that their contamination level varies from one region to the other in a country (Kimanya et al., 2008). Though research have shown that most of the mycotoxin contamination is caused by environmental conditions that favour mould growth, other emerging contributing factors have been through the process of harvesting and storage (Nazareth et al., 2020). Santos (Santos Pereira, C Cunha, \& Fernandes, 2019), in his study found that climatic conditions are the major Agri system that enables colonization and growth of fungi. Still, climate change has continued to cause more significant impact that has compromised the quality of feeds and food (Medina, Akbar, Baazeem, Rodriguez, \& Magan, 2017). Apart from environmental factors, other factors of importance include; Physical, chemical, and Biological, with little focus on their interventions that would reduce contamination (Garcia et al., 2012).

Mould growth depends explicitly on humidity with a moisture content of $0.75-0.85$ aw and temperature ranging between $20^{\circ} \mathrm{C}$ and $30^{\circ} \mathrm{C}$ for significant production of mycotoxin (Peter Mshelia et al., 2020). Aflatoxin and Fumonisin are the most common mycotoxins found in most African countries, especially along the equator (Koskei et al., 2020). Depending on the species, each mycotoxin grows in different conditions; Aflatoxin grows at $33^{\circ} \mathrm{C}$ and moisture content of 0.99 aw; and for Fumonisin, they grow between $18-25 \mathrm{C}$ and at moisture content of 0.93 -0.995aw (Santos Pereira et al., 2019). Therefore, it is important to note their difference to enable proper interventions that target specific toxins. Several researches have shown that moisture content is the crucial component to mycotoxin growth with optimal temperature. Subsequently, there is a clear indication that both Fumonisin and aflatoxin are found in parts of Kenya in warm, humid, and hot deserts as shown in fig 2 below (Camardo Leggieri, Pietri, \& Battilani, 2020). Therefore, it can be concluded that some of the strategies to reduce contamination should focus on mostly Agri techniques including planting of hybrid crops and timely harvesting. 
Reports from parts of Nyeri and lower Eastern where they experienced Aflatoxin outbreaks and high frequencies of Fumonisin showed that most of the contamination was due to poor handling of feeds and storage practices (Mwihia et al., 2018). Although there were other non -infectious factors, i.e., the bioavailability of micronutrients, which were found to play a significant role, further research would better understand a wholesome strategy on control management of contamination (Milani, 2013). Insect damage to cereals was also found to compromise quality of fish feed; different pests were found to invade during harvest to produce toxins through interactions from biological agents and post-harvest (Peter Mshelia et al., 2020).

A survey conducted in five other counties in Kenya representing different Agri - ecological zones: Isiolo, Kwale, Meru, Bungoma, and Tharaka-Nithi by (Senerwa et al., 2016), found that Aflatoxin levels were high compared to WHO standards of $10 \mu \mathrm{g} / \mathrm{kg}$ in both the animal feeds and milk during the rainy season. Further, the contamination from the feeds was from manufacturing industries which were attributed to poor storage. This was also compared with a study by (Njeru et al., 2019) in other five counties in western Kenya of the same Agri ecological characteristics: Siaya, Migori, Vihiga, Kakamega, and Kisumu, showed that climatic conditions influenced contamination of maize in the farms. However, the results suggested that Fumonisin was economically significant, and only a tiny proportion of Aflatoxin was detected. Therefore, it can be concluded that there is evidence of co -occurrence with influence of climatic conditions that are related to humidity and temperature.

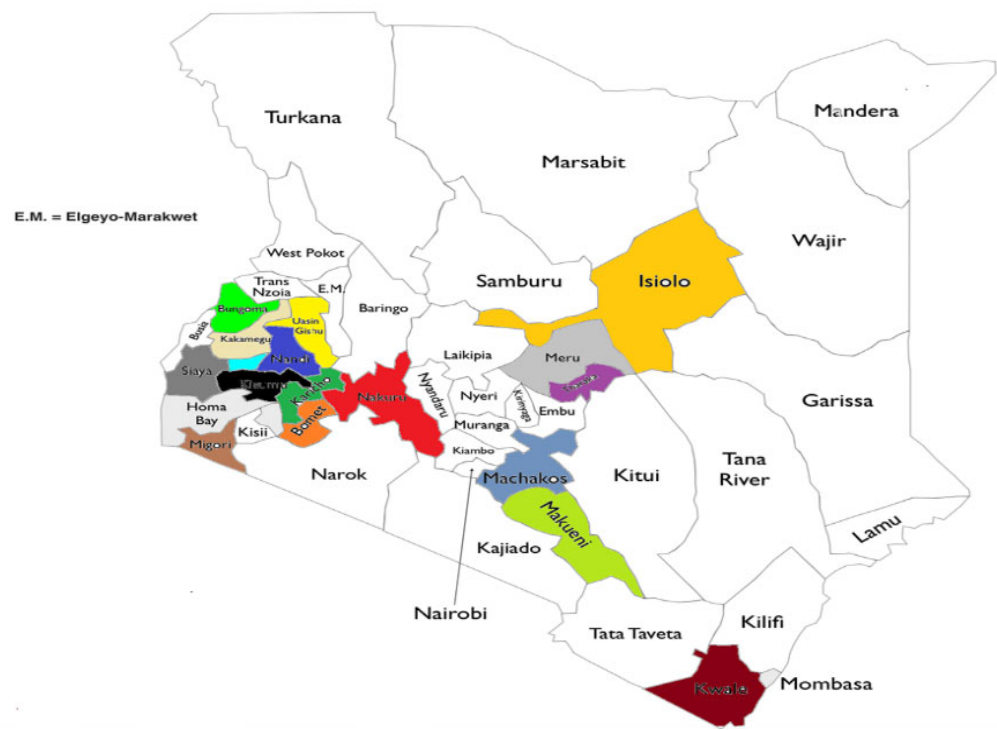

Fig 2: Map of Kenya showing the occurrence of Aflatoxin and Fumonisin in various counties

\section{Exposure of fish to Aflatoxin and Fumonisin}

Fish feeds are prepared from different cereal products commonly contaminated by Mycotoxins (Namulawa et al., 2020). But controlling the growth of fungi that cause mycotoxin has been a challenge due to conditions that enables their development even after putting lots of strategies (Peter Mshelia et al., 2020). The growth of Aquaculture in Kenya has continuously been faced with several challenges, such as the unavailability of good quality and affordable fish feeds; this is because of multiple contributing factors that require better know-how (Oliveira \& Vasconcelos, 2020). Both commercial and locally made fish feeds are the highest contributors to fish production and significantly impact the economic returns from fish farming(Wong, Mo, Choi, Cheng, \& Man, 2016). According to Wilkister Muturi, pre and post-harvesting are the most critical times, but most of our Kenyan farmers practice poor handling of cereals, especially maize, leading to direct contamination during preparation of fish feed exposing fish (Moturi, 2008).

In comparison with other studies done in three counties in Kenya (Kericho, Nakuru, and Bomet) majority of fish farmers were making their feeds locally using available plant wastes like rice, cotton meal, cotton seeds, and sunflower, which might have been contaminated and in turn use as feeds. While on the other side, others were grounding them manually and hand mixing to make pellets subjecting the feeds to contamination (Marijani et al., 2019). Other practices that impede management include time interval of drying maize, and that in most parts where maize is grown, drying up to approximately $20 \%$ moisture content has been a challenge. After harvesting, cereals are stored before being used in traditional galleries and large stores, exposing them to favourable conditions for fungi growth(Aanyu \& Ondhoro, 2016). Prolonged storage with high temperature and humid conditions contributes to fungi' development, compromising the quality of feeds (Marijani et al., 2019). Therefore, farmers and the general public should be aware of the importance of proper drying of cereals and reducing storage time to reduce exposure. 


\section{Decontamination of feed and feed ingredients}

Due to the increased challenges that have led to the loss of economy among farmers and processors, most of them developed strategies to reduce contamination or prevent an attack from mould produce toxins. And by doing so, there has been a positive reduction of contamination and reduced Aflatoxin outbreaks in prone areas, specifically in Makueni and Machakos. Decontamination is a process of deactivating or removing, or destroying toxins in feeds or feed ingredients used as animal feed, and this can be achieved by using different methods. According to Oliveira, few farmers used the biotechnology method to achieve bio-reservation of corn kernels and corn ears with observed positive effects (Oliveira \& Vasconcelos, 2020). For those who had used the technique, a cell-free supernatant spray is applied to the surface of the corn to cover and protect the cereal from the growth of moulds or contamination. And further research showed a reduction of Aflatoxin B1 production by $99.7 \%$ at days 25 and 40, respectively showing a positive response against time.

Recently, with advancement in technology, feed manufacturers and processors opted to use Ultra Violet (UV) as a detoxifying agent for Aflatoxin. But according to Barbosa, he discovered that irradiation of up to 362 activates the toxin and as well increases its susceptibility to degeneration (Barbosa et al., 2013). The method is shown to be expensive and requires specific skills, meaning not most farmers and processors can use it. There are other identified traditional methods used (Reiter, Zentek, \& Razzazi, 2009), these methods include identifying rotten grains and sorting them, winnowing, washing in combination with dehulling of grains with others cleaning their galleries/ store before loading new harvests. These methods have continuously been applied with positive results because most farmers confirmed reduced contamination and found that the traditional methods were cost-effective and straightforward. Therefore, it can be advocated for use because it creates room for quick adaptation. With advanced technology, farmers also access chemicals, with the commonest being pesticides (Barbosa et al., 2013). Most researchers alluded that although the use of pesticides could reduce or control pests from invading cereals especially after drying, most farmers have not always been practising its use and those who have used reported experienced deaths associated with its use (C. Chen, Mitchell, et al., 2018). However, this could explain some of the reasons for the increased mortality that have been associated with the consumption of maize in parts of eastern Kenya in the recent past.

\section{Effects of Aflatoxin and Fumonisin to fish.}

\section{a. Effects of Aflatoxin on fish health}

Mycotoxins are known to cause both chronic and acute conditions on fish health. They cause-specific requirements depending on the age and species of the fish. Studies in Kenya show that there has been a significant loss of fish due to effects caused by exposure to Aflatoxin (Namulawa et al., 2020). Despite efforts geared towards boosting aquaculture, Kenya still experiences many losses because their exposure has negatively impacted the economy because of continuous high mortality. Fish exposed to Aflatoxins develop both physiological and pathophysiological changes with acute conditions that include; cataracts and blindness due to damage of the eye opacity, a condition that has been observed across most fish species. Other common effects observed in different fish are; yellowing of the body, tail rot, abnormal swimming with noted reduced appetite (B. Yu et al., 2019). Oliveira (Oliveira \& Vasconcelos, 2020) found also that fish exposed to aflatoxin exhibited pale gills; with most of them experiencing poor growth rate affecting their weight gains and decreased survival rates because some of them die instantly. Studies from Nyeri county showed observed acute conditions in Tilapia; swollen abdomen, muscular hemorrhages, poor appetite, and growth. Buno (Lala et al., 2020) also found that exposing Nile tilapia fingerlings to Aflatoxin disrupted their behaviour. He further found that for chronic conditions, the toxins modify their fatty acids by increasing the amount of saturated and polyunsaturated fatty acids and as well decreases the levels of monosaturated fatty acids. Other conditions observed in several studies are; Tumour lesions, necrosis, cystic swellings, enlarged hearts, liver, and kidneys. Therefore, it will be prudent to conclude that exposure of fish for a long time causes chronic conditions and also increases chances of toxins accumulation in their tissues.

\section{b. Effects of Fumonisin to fish health}

Fumonisin susceptibility is more specific to particular fish with FB1 toxin inducing organ damage, growth retardation, and immunosuppression increasing cancers and hence mortality (Reis, Oliveira, Zorzete, Faria, \& Corrêa, 2020). According to (Stockmann-Juvala \& Savolainen, 2008), he discovered that this type of mycotoxins causes a wide range of biological effects, including but not limited to leukoencephalomalacia in horses, pulmonary edema in pigs, and nephrotoxicity and liver cancer in rats. Exposure to fish has also exhibited several effects not limited to acute toxicity and chronic conditions. Unlike Aflatoxin that is susceptible to age and species of the fish, Fumonisin affects all species with low toxicity to the kidneys and liver. According to Pietsch, each species and age of fish has its level of sensitivity, with younger fish being more susceptible (Pietsch, 2019). This could also be explained through their rate of metabolism of FB1 in the liver by the younger species. Mortalities have been shown mainly as the profound known acute condition which occasionally happens with Fumonisin, unlike Aflatoxin. Prolonged Fumonisin exposure has been majorly the cause of chronic conditions 
like cancer in humans, but there has been an increasingly high frequency of hepatocellular cancer (Mutiga et al., 2015). Reproductive conditions have also been shown to occur among specific species, and that most of the fish experience observed decrease in ovary weight fecundity with decreased egg size, specifically in gibel carp (Marijani et al., 2019). Other conditions in Tilapia were adverse effects on gonadosomatic index, leading to lowered sperm counts. However, the effects of Fumonisin can be more chronic but with a more significant impact that would affect the production of fish or their yield.

\section{Effects of Aflatoxin and Fumonisin on human}

\section{a. Effects of Aflatoxin on human health}

Mycotoxins cause both acute and chronic diseases in humans, depending on the length of exposure and amount exposed (Benkerroum, 2020a). In a survey done in selected households of Machakos county, it was found that out of the 68 cases of Aflatoxicosis, 20 died making a case fatality of 30\% (Kamala et al., 2018). Different individuals react differently with toxin exposure, and that research have shown its exposure to be attributed to factors including those already with compromised immunity. Among the cases, most of them presented with diarrhea, ascites, jaundice, and abdominal pains with suspicion of homegrown maize contaminated with high levels of aflatoxins $(2.4-285 \mu \mathrm{g} / \mathrm{Kg})$. Further, confounding factors were found to be patients with serum aflatoxin biomarker were showed to be more likely to have higher Aflatoxin-albumin adduct than their control (odds Ratio $=13.5$ ). Therefore, there is evidence that the clinical presentations and high levels of the toxins among the casualties supported the causal role of Aflatoxin. Similar cases from different counties showed high toxicities; hence, it cabe concluded that Aflatoxin would exhibit some toxic effects even in small concentrations.

Fouad (2019) found that apart from the acute conditions caused by Aflatoxins, several other known diseases due to chronic exposure are not limited to estrogenic, immunosuppression, teratogenicity, mutagenicity, and cytotoxicity(Fouad et al., 2019). Benkerroum (Benkerroum, 2020b) explained that exposure of Aflatoxins to low doses or concentrations over time has exhibited to cause cancer with its dietary intake mainly causing primary liver cancer. Other organs of interest include the kidney, pancreas, bladder, and viscera, which have recently elicited lots of concern with rising cancer cases. Therefore, further research is needed to understand this phenomenon and develop strategies to reduce its risks.

Also, (Beitane \& Klava, 2013) said that Aflatoxin is believed to be involved with nutritional disorders that cause kwashiorkor and growth retardation among under five years of age. But Turner suggested that probably Aflatoxin could be interfering with protein synthesis, enzyme activities, and hence associating with poor absorption of some micronutrients (Zinc, iron, and vitamins) (Turner, 2013). Aflatoxin exposure has been known to be through direct consumption of contaminated food, bioaccumulation that follows the food chain but for young children, it can occur throughout their lifetime starting from utero or transplacental (Gong, Watson, \& Routledge, 2016). Exposure through breastmilk has been less toxic; however, many Kenyan children are considered exposed during weaning because the typical weaning food is cereal-based. Evidence from epidemiological studies, especially in some parts of Africa comprising young children of 5years, showed a positive correlation between aflatoxin exposure and growth retardation (C. Chen, Mitchell, et al., 2018). Currently, malnutrition and child growth impairment are becoming a significant public health burden in Africa and Kenya. There has been little understanding between Aflatoxin and child growth, considering other factors that could influence like poverty, hunger, and infectious diseases. It is critical then to elucidate the mechanisms behind the effects of both Aflatoxin and Fumonisin on child growth.

On the other side, Vitamin E is responsible for human immune functions especially in people who experience immunosuppression. It is documented that HIV and Hepatitis B patients experience significantly lower concentrations of plasma vitamins (Vit. A \& E) when exposed to high levels of Aflatoxin (Obuseh et al., 2011). Other prospective studies have also shown that low serum vitamin $\mathrm{E}$ is associated with HIV disease progression. It can therefore be concluded that there is mounting evidence implicating Aflatoxin contamination with a negative impact to immune suppression and malabsorption of micronutrients, especially in children and patients with chronic illnesses like cancer, HBV, and HIV with noted progression (Misihairabgwi, Ezekiel, Sulyok, Shephard, \& Krska, 2019).

\section{b. Effects of Fumonisin on human health}

The International Agency for Research on Cancer (IARC) had declared F. moniliforme toxins as potentially carcinogenic to humans and categorized it as a Class 2B carcinogen (Kigen et al., 2017; Ostry, Malir, Toman, \& Grosse, 2017). There has been evidence of the toxin associated with a high incidence of oesophageal cancer in human exposure, especially in Western Kenya where maize is grown in high yield and is used to prepare animal feed and traditional alcohol through fermentation (Alizadeh et al., 2012). Though research shows that fermentation in contaminated food increases the chances of mycotoxin consumption, experimental studies have demonstrated a reduction of its levels if done within 72 hours. Fermentation has been considered another alternative mechanism of removing toxic contaminants through natural methods or lactic acid bacteria that open up aflatoxin lactone ring resulting in detoxification (Cheng, Vella, \& Stasiewicz, 2019). However, if this method 
is considered, it is easier to ferment the ingredients than animal feeds.

\section{Risk Characterization}

The amount of mycotoxins consumed contributes to the mutagenic, carcinogenic, teratogenic, and immunosuppressive health effects in the body. The adverse impact of Aflatoxins and Fumonisin in humans ranges from acute hepatic toxicity to chronic diseases such as liver cancer, hemorrhages, edema, and even immediate death. Risk characterization of the above mycotoxins in Kenya shows that; the likelihood of the toxin entering the food chain is very high given the fact that most fish farmers and traders are contributing towards contamination of fish feeds. This has been found to be through poor handling, storage and as well as the long storage period, especially with farmers who are practising large scale farming. According to Radley, he alluded that the amount of mycotoxins entering the food chain depends on the feeds fed to animals (Ráduly, Szabó, Madar, Pócsi, \& Csernoch, 2020). It has been noticed that several fish feed provided in Kenya are prepared from ingredients that are either contaminated with aflatoxins or Fumonisin, thus increasing the chances of contamination.

Table: 1 Risk Characterization

\begin{tabular}{|l|l|l|l|l|l|l|}
\hline \multicolumn{2}{|c|}{} & \multicolumn{5}{c|}{ Severity } \\
\cline { 3 - 7 } \multicolumn{2}{|c|}{} & 5 & 4 & 3 & 2 & 1 \\
\hline Likelihood & 5 & 25 & 20 & 15 & 10 & 5 \\
\hline \multirow{5}{*}{} & 4 & 20 & 16 & 12 & 8 & 4 \\
\cline { 2 - 7 } & 3 & 15 & 12 & 9 & 6 & 3 \\
\cline { 2 - 7 } & 2 & 10 & 8 & 6 & 4 & 2 \\
\cline { 2 - 7 } & 1 & 5 & 4 & 3 & 2 & 1 \\
\hline
\end{tabular}

The risk characterization of both Aflatoxins and Fumonisin. 15-25 is High Risk, 8-12 is Moderate Risk, 1-6 is Low Risk.

Overall, contamination of fish feeds with mycotoxins is a global concern with its prevalence of contamination depending on geographical conditions. From the evidence shown, the likelihood of fish feed being exposed to contamination is high and can be rated at scale five, as shown in Figure 2. The occurrence follows the Agrieconomic zones and the climatic conditions that cut across the counties with a high prevalence of mycotoxins. Kenya is a developing country that have little capacity and therefore cannot control the exposure of fish or fish feed to mycotoxin contamination. Several studies from different region of the country have shown that most fish feeds that are available are prepared using cereal crops that have been shown to be most likely to be exposed to contamination. This is due to a lack of awareness of causal and measures to mitigate the increase of aflatoxins and Fumonisin contaminated feeds (Mutegi, Cotty, \& Bandyopadhyay, 2018). Financial constraints have also led to farmers' increased stock of feeds by purchasing cheap feeds at low prices hence compromising the quality and chances of purchasing contaminated feeds.

In terms of severity, a scale of 1-5 was used to indicate exposure-outcome. Consumption of Aflatoxins and Fumonisin by fish and humans exhibited various effects ranging from death to acute and chronic conditions. Table 1 above is colour coded with the red colour denoting high risk, yellow for moderate, and green for the low risk. Though both toxins exhibited different levels of toxicity, they also exhibited chronic conditions after prolonged exposure. Fish was at high risk due to high mortality cases observed with high chances of developing acute conditions and chronic conditions. Consumption of contaminated fish by humans through bioaccumulation has shown chronic illnesses, with most of them growing cancers. Therefore, the risk of aflatoxins and Fumonisin in Kenya concerning contamination of fish feed is categorized to be at 20. Due to this, integrated strategies are to be developed to ensure reduced exposure by either destroying or eliminating the toxin. Other methods could follow transforming them into less toxic derivatives, which can be done using adsorbents or reducing chemicals (Karlovsky et al., 2016).

\section{Management and risk reduction of Aflatoxin and Fumonisin}

Mycotoxin is potentially carcinogenic for decades, and therefore their quantities in food and animal feed have been of concern in many countries prompting close monitoring and regulations on their limits (Panahi, Kasaee, Mokhtari, Sharifi, \& Jangjou, 2011). In the past, most countries and regions have considered setting maximum tolerable limits for each mycotoxin in animal feeds and food. But most African countries exceed the European Union maximum limits simply because they lack proper and effective management strategies controlling their levels (Kebede, Liu, Jin, \& Xing, 2020). Several studies have confirmed that most mycotoxins contamination is environmentally dependent with several management practices that are already in use in different regions that are experiencing frequent contamination. But according to (Kebede et al., 2020), the commonly used methods are geared towards preventive agricultural practices that would minimize contamination applied during pre and postharvesting. However, Liu (Liu et al., 2016) considered identifying pre- harvesting, storage, and feed processing 
as critical control points of applying management strategies. He further selected some of the parameters to be monitored and controlled to be including temperature and moisture contents. Other researchers agreed that storage conditions play a significant role in mould growth and that environmental factors should be controlled coupled with appropriate packaging materials and proper ventilation during storage (Agriopoulou, Stamatelopoulou, \& Varzakas, 2020).

Zhang (Liu et al., 2016) described that different countries had adopted various practices aligned to specific code of practices developed by the FAO/WHO, 2001 and primarily used in Southern Asia. The specific codes of practices for Fumonisin control were designed and made in use in 2013 including the national code of practice for cereals SAC, 2008, which is commonly used in China. In a study done in Kenya by (Moturi, 2008) they found that pre and post-harvesting practices are the critical time of control with interval drying of maize and concluded that as they start drying up, its moisture content should reduce up to $20 \%$ which is a challenge to most farmers. Though Kenyan farmers have their feed ingredients that include cereals harvested, shelled and sun-dried before storing in traditional galleries they do not consider proper ventilation as a factor. Some of the management strategies employed in Kenya are summarised in the table below;

Table: 2 Management Strategies

\begin{tabular}{|c|c|c|c|}
\hline & $\begin{array}{l}\text { Stages in the development of } \\
\text { feed ingredients and feeds }\end{array}$ & Strategies applied to reduce contamination & References \\
\hline 1 & Pre-Harvest & $\begin{array}{l}\text {-Use of Genotyped seeds } \\
\text {-Timely harvest when the crops are mature } \\
\text {-Cultural/Agricultural practices; Tilling timely } \\
\text { planting and crop rotation }\end{array}$ & $\begin{array}{l}\text { (Unnevehr \& Grace, } \\
\text { 2013) } \\
\text { (Mutegi et al., 2018) }\end{array}$ \\
\hline 2 & $\begin{array}{l}\text { Post-harvest (Drying and } \\
\text { Storage) }\end{array}$ & $\begin{array}{l}\text {-Sorting damaged grains-Done manually based } \\
\text { on; the infected, those with physical damage, } \\
\text { discolouration due to mould infestation, and size } \\
\text {-Sun drying, drying maize on stakes in the field } \\
\text {-Grain preservation using specific chemicals } \\
\text { 9Maize and Sorghum) }\end{array}$ & $\begin{array}{l}\text { (Owiro, Rachuonyo, } \\
\text { Ochuodho, \& Gohole, } \\
\text { 2019) } \\
\text { (Unnevehr \& Grace, } \\
\text { 2013) }\end{array}$ \\
\hline 3 & $\begin{array}{l}\text { Feed preparation, handling, and } \\
\text { storage }\end{array}$ & $\begin{array}{l}\text {-Use of Polypropylene and hermetic bags for } \\
\text { packaging } \\
\text {-Surveillance- Use of moisture meter with rapid } \\
\text { test kits for monitoring }\end{array}$ & $\begin{array}{l}\text { (Kang'ethe, 2011) } \\
\text { (Marete et al., 2019 }\end{array}$ \\
\hline 4 & Creation of awareness & $\begin{array}{l}\text { Training of farmers and traders 0n; -Effects of } \\
\text { mycotoxins in fish feeds, good agricultural } \\
\text { practices that reduce contamination }\end{array}$ & (Marete et al., 2019) \\
\hline
\end{tabular}

Risks to human have been assumed to happen when toxin concentrations have exceeded the safety limits and duration of exposure (X. Yu, Liu, Xie, Zheng, \& Li, 2012). Risk reduction strategies are applied to reduce these risks in humans and animals focused on dietary changes, chemoprevention, detoxification, and vaccination (Afolabi et al., 2020). Studies have shown that humans who suffer from Hepatitis B have more chances of up to 30-fold elevated to acquiring cancer risk from Aflatoxin than those without and are exposed (J.-G. Chen et al., 2013). Therefore, to reduce this risk Wild and Gong, 2010 discovered that vaccination of humans with Hepatitis B would reduce chances of liver cancers when exposed to Aflatoxin. The use of additives in animal feeds has also shown decreased bioavailability of toxin-producing fungi (Nakavuma et al., 2020). Several types of research have been done on clay additives, such as Bentonites, hydrated aluminium silicate (HSCAS), Zeolite, and Saprolite. These additives have shown positive results through improved physical properties of animal feeds and allowed absorption of Aflatoxin(Omasaki, Charo-Karisa, \& Kosgey, 2013).

According to (Limaye, Yu, Chou, Liu, \& Cheng, 2018), he also found that nutritional agents hold great potential to be ant Aflatoxin B1 supplements. Selenium application to animal feeds is a growing discipline that has indicated promising reports to ameliorate Aflatoxicosis. Others include curcumin, which has also been demonstrated to be a potent ameliorating agent used to counteract AFB1 to mediate oxidative liver damage in animals and humans. But according to (Dorner \& Horn, 2007) they asserted by concluding that if the lowest possible levels of mycotoxin contamination are to be achieved, all the management strategies should be combined to ensure a safe supply of sustainable raw materials.

\section{Conclusion}

The review has shown that feeds and feed ingredients are vulnerable to mycotoxin contamination attributed to poor management processes from transportation, handling and storage. Mycotoxins can be carried over from fish feeds to humans by ingesting contaminated fish and fish products, causing potential health risks to human and fish health. Therefore, it is essential to consider combining all possible management and preventive strategies to include good agricultural practices, creating awareness to the public and farmers, and routine monitoring of feeds 
and storage facilities.

\section{References}

Aanyu, M., \& Ondhoro, C. (2016). Effects of storage duration on proximate composition of non-conventional fish feed ingredients and farm-made feed. Journal of Global Agriculture and Ecology, 6(3), 162-169.

Afolabi, C. G., Ezekiel, C. N., Ogunbiyi, A. E., Oluwadairo, O. J., Sulyok, M., \& Krska, R. (2020). Fungi and mycotoxins in cowpea (Vigna unguiculata L) on Nigerian markets. Food Additives \& Contaminants: Part B, 13(1), 52-58.

Agriopoulou, S., Stamatelopoulou, E., \& Varzakas, T. (2020). Advances in occurrence, importance, and mycotoxin control strategies: prevention and detoxification in foods. Foods, 9(2), 137.

Alizadeh, A. M., Roshandel, G., Roudbarmohammadi, S., Roudbary, M., Sohanaki, H., Ghiasian, S. A., . . . Aghasi, M. (2012). Fumonisin B1 contamination of cereals and risk of esophageal cancer in a high risk area in northeastern Iran. Asian Pacific Journal of Cancer Prevention, 13(6), 2625-2628.

Barbosa, T. S., Pereyra, C. M., Soleiro, C. A., Dias, E. O., Oliveira, A. A., Keller, K. M., . . Rosa, C. A. (2013). Mycobiota and mycotoxins present in finished fish feeds from farms in the Rio de Janeiro State, Brazil. International Aquatic Research, 5(1), 3.

Beitane, I., \& Klava, D. (2013). Microbiological Assessment of Yoghurt Enriched with Flakes from Barley Grain and Malt Extract during Shelf-Life. International Journal of Nutrition and Food Engineering, 7(8), 763-766.

Benkerroum, N. (2020a). Aflatoxins: Producing-Molds, Structure, Health Issues and Incidence in Southeast Asian and Sub-Saharan African Countries. International journal of environmental research and public health, 17(4), 1215.

Benkerroum, N. (2020b). Chronic and acute toxicities of aflatoxins: mechanisms of action. International journal of environmental research and public health, 17(2), 423.

Camardo Leggieri, M., Pietri, A., \& Battilani, P. (2020). Modelling fungal growth, mycotoxin production and release in grana cheese. Microorganisms, 8(1), 69.

Chen, C., Mitchell, N. J., Gratz, J., Houpt, E. R., Gong, Y., Egner, P. A., . . Svensen, E. (2018). Exposure to aflatoxin and fumonisin in children at risk for growth impairment in rural Tanzania. Environment international, 115, 29-37.

Chen, C., Riley, R. T., \& Wu, F. (2018). Dietary fumonisin and growth impairment in children and animals: A review. Comprehensive Reviews in Food Science and Food Safety, 17(6), 1448-1464.

Chen, J.-G., Egner, P. A., Ng, D., Jacobson, L. P., Muñoz, A., Zhu, Y.-R., . . . Groopman, J. D. (2013). Reduced aflatoxin exposure presages decline in liver cancer mortality in an endemic region of China. Cancer prevention research, 6(10), 1038-1045.

Cheng, X., Vella, A., \& Stasiewicz, M. J. (2019). Classification of aflatoxin contaminated single corn kernels by ultraviolet to near infrared spectroscopy. Food Control, 98, 253-261.

Dorner, J. W., \& Horn, B. W. (2007). Separate and combined applications of nontoxigenic Aspergillus flavus and A. parasiticus for biocontrol of aflatoxin in peanuts. Mycopathologia, 163(4), 215-223.

Fouad, A. M., Ruan, D., El-Senousey, H. K., Chen, W., Jiang, S., \& Zheng, C. (2019). Harmful effects and control strategies of aflatoxin b1 produced by Aspergillus flavus and Aspergillus parasiticus strains on poultry. Toxins, 11(3), 176

Garcia, D., Barros, G., Chulze, S., Ramos, A. J., Sanchis, V., \& Marín, S. (2012). Impact of cycling temperatures on Fusarium verticillioides and Fusarium graminearum growth and mycotoxins production in soybean. Journal of the Science of Food and Agriculture, 92(15), 2952-2959.

Gong, Y. Y., Watson, S., \& Routledge, M. N. (2016). Aflatoxin exposure and associated human health effects, a review of epidemiological studies. Food safety, 4(1), 14-27.

Kamala, A., Shirima, C., Jani, B., Bakari, M., Sillo, H., Rusibamayila, N., . . Simba, A. (2018). Outbreak of an acute aflatoxicosis in Tanzania during 2016. World Mycotoxin Journal, 11(3), 311-320.

Kang'ethe, E. (2011). Situation analysis: improving food safety in the maize value chain in Kenya. A report prepared for FAO. College of Agriculture and Veterinary Science, University of Nairobi, Nairobi.

Karlovsky, P., Suman, M., Berthiller, F., De Meester, J., Eisenbrand, G., Perrin, I., . . Recker, T. (2016). Impact of food processing and detoxification treatments on mycotoxin contamination. Mycotoxin research, 32(4), 179-205.

Kebede, H., Liu, X., Jin, J., \& Xing, F. (2020). Current status of major mycotoxins contamination in food and feed in Africa. Food Control, 110, 106975.

Kigen, G., Busakhala, N., Kamuren, Z., Rono, H., Kimalat, W., \& Njiru, E. (2017). Factors associated with the high prevalence of oesophageal cancer in Western Kenya: a review. Infectious agents and cancer, 12(1), 59.

Kimanya, M. E., De Meulenaer, B., Tiisekwa, B., Ndomondo-Sigonda, M., Devlieghere, F., Van Camp, J., \& Kolsteren, P. (2008). Co-occurrence of fumonisins with aflatoxins in home-stored maize for human 
consumption in rural villages of Tanzania. Food additives and contaminants, 25(11), 1353-1364.

Koskei, P., Karanja, S., Mashedi, O., Tetsuhiro, M., Tohru, G., Takashi, Y., \& Bii, C. (2020). Isolation and Characterization of Fusarium Species and Fumonisins Contamination in Maize from Lower Eastern and Rift Valley Regions of Kenya. African Journal of Education, Science and Technology, 6(1), 19-28.

Lala, B., Santos, C. T., Roldi, G., de Oliveira Roça, R., Garcia, A. L. S., Gianeti, T., . . Paolozzi, R. (2020). Challenge with fumonisin FB1+ FB2 alters profile of fatty acids in Nile tilapia fingerlings. Aquaculture, $516,734546$.

Limaye, A., Yu, R.-C., Chou, C.-C., Liu, J.-R., \& Cheng, K.-C. (2018). Protective and detoxifying effects conferred by dietary selenium and curcumin against AFB1-mediated toxicity in livestock: a review. Toxins, $10(1), 25$.

Liu, Z., Zhang, G., Zhang, Y., Jin, Q., Zhao, J., \& Li, J. (2016). Factors controlling mycotoxin contamination in maize and food in the Hebei province, China. Agronomy for Sustainable Development, 36(2), 39.

Makau-Barasa, L. K., Greene, S., Othieno-Abinya, N., Wheeler, S. B., Skinner, A., \& Bennett, A. V. (2020). A review of Kenya's cancer policies to improve access to cancer testing and treatment in the country. Health Research Policy and Systems, 18(1), 1-10.

Marete, G. N., Kanja, L. W., Mbaria, J. M., Okumu, M. O., Ateku, P. A., Korhonen, H., \& Joutsjoki, V. (2019). Effects of the Use of good agricultural practices on aflatoxin levels in maize grown in Nandi county, Kenya. Sci, 1(1), 28.

Marijani, E., Charo-Karisa, H., Kigadye, E., \& Okoth, S. (2020). Occurrence and Exposure Assessment of Aflatoxin B1 in Omena (Rastrineobola argentea) from Kenya. Journal of Food Quality, 2020.

Marijani, E., Kigadye, E., \& Okoth, S. (2019). Occurrence of Fungi and Mycotoxins in Fish Feeds and Their Impact on Fish Health. International Journal of Microbiology, 2019.

Medina, A., Akbar, A., Baazeem, A., Rodriguez, A., \& Magan, N. (2017). Climate change, food security and mycotoxins: do we know enough? Fungal Biology Reviews, 31(3), 143-154.

Milani, J. (2013). Ecological conditions affecting mycotoxin production in cereals: a review. Veterinarni Medicina, 58(8).

Misihairabgwi, J., Ezekiel, C., Sulyok, M., Shephard, G., \& Krska, R. (2019). Mycotoxin contamination of foods in Southern Africa: A 10-year review (2007-2016). Critical reviews in food science and nutrition, 59(1), 43-58.

Moretti, A., Logrieco, A. F., \& Susca, A. (2017). Mycotoxins: An underhand food problem Mycotoxigenic fungi (pp. 3-12): Springer.

Moturi, W. K. N. (2008). Factors likely to enhance mycotoxin introduction into the human diet through maize in Kenya. African Journal of Food, Agriculture, Nutrition and Development, 8(3), 265-277.

Munguti, J. M., Kim, J.-D., \& Ogello, E. O. (2014). An overview of Kenyan aquaculture: Current status, challenges, and opportunities for future development. Fisheries and Aquatic sciences, 17(1), 1-11.

Mutegi, C., Cotty, P., \& Bandyopadhyay, R. (2018). Prevalence and mitigation of aflatoxins in Kenya (1960-to date). World Mycotoxin Journal, 11(3), 341-357.

Muteti, M. K., Lokuruka, M. N., \& Yasindi, A. W. (2019). Socio-economic Factors Influencing Nile Tilapia Aquaculture in Kenya. Journal of Food and Nutritional Sciences Research, 1(1), 41-50.

Mutiga, S. K., Hoffmann, V., Harvey, J. W., Milgroom, M. G., \& Nelson, R. J. (2015). Assessment of aflatoxin and fumonisin contamination of maize in western Kenya. Phytopathology, 105(9), 1250-1261.

Mwihia, E. W., Mbuthia, P. G., Eriksen, G. S., Gathumbi, J. K., Maina, J. G., Mutoloki, S., . . . Lyche, J. L. (2018). Occurrence and levels of aflatoxins in fish feeds and their potential effects on fish in Nyeri, Kenya. Toxins, 10(12), 543.

Nakavuma, J. L., Kirabo, A., Bogere, P., Nabulime, M. M., Kaaya, A. N., \& Gnonlonfin, B. (2020). Awareness of mycotoxins and occurrence of aflatoxins in poultry feeds and feed ingredients in selected regions of Uganda. International Journal of Food Contamination, 7, 1-10.

Namulawa, V. T., Mutiga, S., Musimbi, F., Akello, S., Ngángá, F., Kago, L., . . G Ghimire, S. (2020). Assessment of Fungal Contamination in Fish Feed from the Lake Victoria Basin, Uganda. Toxins, 12(4), 233.

Nazareth, T. d. M., Luz, C., Torrijos, R., Quiles, J. M., Luciano, F. B., Mañes, J., \& Meca, G. (2020). Potential Application of Lactic Acid Bacteria to Reduce Aflatoxin B1 and Fumonisin B1 Occurrence on Corn Kernels and Corn Ears. Toxins, 12(1), 21.

Nazhand, A., Durazzo, A., Lucarini, M., Souto, E. B., \& Santini, A. (2020). Characteristics, Occurrence, Detection and Detoxification of Aflatoxins in Foods and Feeds. Foods, 9(5), 644.

Njeru, N. K., Midega, C. A. O., Muthomi, J. W., Wagacha, J. M., \& Khan, Z. R. (2019). Influence of socio-economic and agronomic factors on aflatoxin and fumonisin contamination of maize in western Kenya. Food science \& nutrition, 7(7), 2291-2301.

Nyandat, B. (2007). Analysis of feeds and fertilizers for sustainable aquaculture development in Kenya. FAO FISHERIES TECHNICAL PAPER, 497, 423. 
Nzevu, J. M., Amwata, D. A., \& Mutua, A. K. (2018). Status of socio-economic parameters of fish farmers in Kitui Central Sub-County, Kitui County.

Obonyo, M. A., \& Salano, E. N. (2018). Perennial and seasonal contamination of maize by aflatoxins in eastern Kenya. International Journal of Food Contamination, 5(1), 6.

Obuseh, F. A., Jolly, P. E., Kulczycki, A., Ehiri, J., Waterbor, J., Desmond, R. A., . . Piyathilake, C. J. (2011). Aflatoxin levels, plasma vitamins A and E concentrations, and their association with HIV and hepatitis B virus infections in Ghanaians: a cross-sectional study. Journal of the International AIDS Society, 14(1), 53.

Ochwoto, M., Oduma, C. O., Oyugi, J., Mwaengo, D., Ondigo, B. N., Kimotho, J. H., . . . Songok, E. (2019). Human TP53 gene polymorphisms among patients with hepatocellular carcinoma and chronic hepatitis B in Kenya. F1000Research, 8(1364), 1364.

Oliveira, M., \& Vasconcelos, V. (2020). Occurrence of Mycotoxins in Fish Feed and Its Effects: A Review. Toxins, $12(3), 160$.

Omasaki, S. K., Charo-Karisa, H., \& Kosgey, I. S. (2013). Fish production practices of smallholder farmers in western Kenya. Livestock Research for Rural Development, 25(3), 52.

Ostry, V., Malir, F., Toman, J., \& Grosse, Y. (2017). Mycotoxins as human carcinogens-the IARC Monographs classification. Mycotoxin research, 33(1), 65-73.

Owiro, N., Rachuonyo, H., Ochuodho, J., \& Gohole, L. (2019). Mycotoxin Contamination Risks Due to Handling Practices of Indigenous Chicken Feeds in Kenya. European Journal of Nutrition \& Food Safety, 168-177.

Panahi, P., Kasaee, S., Mokhtari, A., Sharifi, A., \& Jangjou, A. (2011). Assessment of aflatoxin M1 contamination in raw milk by ELISA in Urmia, Iran. American-Eurasian Journal of Toxicological Sciences, 3(4), 231-233.

Peter Mshelia, L., Selamat, J., Iskandar Putra Samsudin, N., Rafii, M. Y., Abdul Mutalib, N.-A., Nordin, N., \& Berthiller, F. (2020). Effect of Temperature, Water Activity and Carbon Dioxide on Fungal Growth and Mycotoxin Production of Acclimatised Isolates of Fusarium verticillioides and F. graminearum. Toxins, $12(8), 478$.

Pietsch, C. (2019). Food safety: the risk of mycotoxin contamination in fish Mycotoxins and Food Safety: IntechOpen.

Ráduly, Z., Szabó, L., Madar, A., Pócsi, I., \& Csernoch, L. (2020). Toxicological and medical aspects of Aspergillus-derived Mycotoxins entering the feed and food chain. Frontiers in Microbiology, 10, 2908.

Rani, S., \& Kumar, P. (2020). Proximate composition analysis of plant-based, Non-conventional feed ingredients having potential as ingredient in fish feed. Journal of Pharmacognosy and Phytochemistry, 9(1), 1853-1859.

Reis, T., Oliveira, T., Zorzete, P., Faria, P., \& Corrêa, B. (2020). A non-toxigenic Aspergillus flavus strain prevents the spreading of Fusarium verticillioides and fumonisins in maize. Toxicon.

Reiter, E., Zentek, J., \& Razzazi, E. (2009). Review on sample preparation strategies and methods used for the analysis of aflatoxins in food and feed. Molecular nutrition \& food research, 53(4), 508-524.

Santos Pereira, C., C Cunha, S., \& Fernandes, J. O. (2019). Prevalent mycotoxins in animal feed: Occurrence and analytical methods. Toxins, 11(5), 290.

Senerwa, D., Sirma, A., Mtimet, N., Kang'ethe, E. K., Grace, D., \& Lindahl, J. F. (2016). Prevalence of aflatoxin in feeds and cow milk from five counties in Kenya. African Journal of Food, Agriculture, Nutrition and Development, 16(3), 11004-11021.

Sirma, A. J., Makita, K., Grace Randolph, D., Senerwa, D., \& Lindahl, J. F. (2019). Aflatoxin exposure from milk in rural Kenya and the contribution to the risk of liver cancer. Toxins, 11(8), 469.

Stockmann-Juvala, H., \& Savolainen, K. (2008). A review of the toxic effects and mechanisms of action of fumonisin B1. Human \& experimental toxicology, 27(11), 799-809.

Strosnider, H., Azziz-Baumgartner, E., Banziger, M., Bhat, R. V., Breiman, R., Brune, M.-N., . . . Hell, K. (2006). Workgroup report: public health strategies for reducing aflatoxin exposure in developing countries. Environmental Health Perspectives, 114(12), 1898-1903.

Sulyok, M., Krska, R., \& Schuhmacher, R. (2010). Application of an LC-MS/MS based multi-mycotoxin method for the semi-quantitative determination of mycotoxins occurring in different types of food infected by moulds. Food Chemistry, 119(1), 408-416.

Tarus, J., Rachuonyo, H., Omega, J., \& Ochuodho, J. (2019). Assessment of Aflatoxin Levels in Indigenous Chicken Tissues and Eggs in Western Kenya. African Journal of Education, Science and Technology, 5(3), 59-65.

Turner, P. C. (2013). The molecular epidemiology of chronic aflatoxin driven impaired child growth. Scientifica, 2013.

Unnevehr, L., \& Grace, D. (2013). Aflatoxins: Finding solutions for improved food safety (Vol. 20): Intl Food Policy Res Inst.

Vitousek, P. M., Naylor, R., Crews, T., David, M., Drinkwater, L., Holland, E., . . Matson, P. (2009). Nutrient 
imbalances in agricultural development. Science, 324(5934), 1519-1520.

Wong, M.-H., Mo, W.-Y., Choi, W.-M., Cheng, Z., \& Man, Y.-B. (2016). Recycle food wastes into high quality fish feeds for safe and quality fish production. Environmental Pollution, 219, 631-638.

Yu, B., Huai, D., Huang, L., Kang, Y., Ren, X., Chen, Y., . . . Chen, W. (2019). Identification of genomic regions and diagnostic markers for resistance to aflatoxin contamination in peanut (Arachis hypogaea L.). BMC genetics, 20(1), 32 .

Yu, X., Liu, Y., Xie, X., Zheng, X.-D., \& Li, S.-M. (2012). Biochemical Characterization of Indole Prenyltransferases Filling The Last Gap Of Prenylation Positions By A 5-Dimethylallyltryptophan Synthase From Aspergillus Clavatus. Journal of Biological Chemistry, 287(2), 1371-1380. 